\title{
Resilience: Measurement
}

Süss, Hannah Christina ; Fischer, Susanne

DOI: https://doi.org/10.1007/978-1-4614-6439-6_51-2

Posted at the Zurich Open Repository and Archive, University of Zurich ZORA URL: https://doi.org/10.5167/uzh-189784

Book Section

Published Version

Originally published at:

Süss, Hannah Christina; Fischer, Susanne (2019). Resilience: Measurement. In: Gellman, Marc. Encyclopedia of Behavioral Medicine (2nd ed). New York: Springer, 1-4.

DOI: https://doi.org/10.1007/978-1-4614-6439-6_51-2 


\section{Resilience: Measurement}

Hannah Süss and Susanne Fischer

Clinical Psychology and Psychotherapy, Institute of Psychology, University of Zurich, Zurich, Switzerland

\section{Synonyms}

Hardiness; Resilience; Sense of coherence measurement

\section{Definition}

Resilience is a relatively stable trajectory of healthy functioning after a potentially stressful event, which is characterized by transient symptoms and minimal impairment.

\section{Description}

The above definition of resilience implies the occurrence of a potential stressor as well as the presence of certain resilience factors, which contribute to a beneficial rather than a pathological outcome (Bonanno 2004; Bonanno and Diminich, 2013; Bonanno et al. 2011). Despite general consensus on the conceptualization of resilience, there are ambiguities in how its components are operationalized.
Regarding potential stressors, operationalization depends on the individual research question and on the population of interest. In studies on children and adolescents, the focus is usually on adverse early life events, such as childhood trauma, or on socioeconomic deprivation as a variant of chronic stress. In adults, trauma occurring during the adult life span, critical life events, and various forms of chronic stress have been the subject of most research. In terms of chronic stress, important topics have been resilience in the face of chronic diseases (e.g., Deshields et al. 2016; Goubert and Trompetter 2017; TanKristanto and Kiropoulos, 2015) and minority stress (e.g., Babatunde-Sowole et al. 2016; Woodward et al. 2017). Most studies adopt selfreported measurement approaches, such as structured interviews or checklists and questionnaires to retrospectively assess potential stressors. Such measures are sometimes complemented by biological parameters, such as brain activity, autonomic, endocrine, or immune parameters, which may serve as indicators of long-lasting physiological changes in response to severe or long-lasting stress.

In order to measure beneficial outcomes after previous exposure to stressors, composite indices across multiple behavioral domains of functioning (e.g., school or recreational activities) are often created in children and adolescents. Also, achievement of developmental milestones can be used as an indicator of successful adaptation. Such measurements commonly rely on 
evaluations and ratings provided by parents or teachers. In contrast, studies investigating adults are mostly designed within clinical contexts. As a consequence, beneficial outcomes equal the absence of somatic symptoms, physical diseases, psychological distress, or mental disorders. The assessment of physical and mental well-being usually relies on self-reported measures, but again, structured interviews may be used to determine the absence or presence of particular illnesses.

There are two types of resilience factors: psychological and biological. In order to assess psychological resilience factors, several questionnaires have been developed over the past decades (Ahern et al. 2006; Pangallo et al. 2015; Windle et al. 2011). Some refer to global resilience constructs, such as sense of coherence (Antonovsky 1979), hardiness (Kobasa 1979), or ego-resiliency (Block and Block 1980). Further global resilience scales are the Resilience Scale (RS; Wagnild and Young 1993), the ConnorDavidson Resilience Scale (CD-RISC; Connor and Davidson 2003), and the Resilience Scale for Adults (RSA; Friborg et al. 2003). The RS was developed based on interviews with community-dwelling older women after experience of critical life events. Principal component analysis of the 25 items revealed two factors labeled "personal competence" and "acceptance of self and life." The scale has been employed in population based as well as clinical contexts. The CD-RISC, by contrast, predominantly consists of questions addressing coping behavior. A preliminary validation study conducted by the authors yielded a structure of five factors based on the 25 items of the test. Application of the instrument has so far mostly been limited to clinical trials. Finally, the RSA also incorporates items on external resilience factors, such as social support. Overall, five dimensions were empirically found to adequately describe the resilience concept as suggested by the authors, namely, personal competence, social competence, family coherence, social support, and personal structure. The scale has been used in studies in both healthy participants and patient samples. Moreover, a number of scales to measure resilience with regard to specific chronic diseases are now available. One example for this is the Resilience Scale Specific to Cancer (RS-SC; Ye et al. 2018). Finally, a number of more specific traits have commonly been associated with resilience, and for all of these, questionnaires are available. These include self-efficacy (Sherer et al. 1982), positive affectivity (Watson et al. 1988), optimism (Scheier et al. 1994), self-esteem (Rosenberg 1965), active coping (Folkman and Lazarus 1988), and social support (Sarason et al. 1983).

While resilience factors have traditionally been examined psychometrically, more recent research has sought to identify biological underpinnings of resilience (Charney, 2004; Feder et al. 2009; Russo et al. 2012). Studies in this area of research usually utilize experimental designs directed at exploring the biological processes involved in beneficial outcomes in the aftermath of a stressor. Concerning neuronal processes, researchers have demonstrated that various brain structures and pathways, such as the medial prefrontal cortex, the hippocampal pathway and the mesolimbic pathway are involved in resilience (Han and Nestler 2017; Liu et al. 2018). In addition, according to Walker et al. (2017), the following markers are particularly promising in serving as biological resilience factors: noradrenaline, corticotropin-releasing hormone $(\mathrm{CRH})$, neuropeptide Y (NPY), the acoustic startle response, cardiovascular stress reactivity (response amplitude), heart rate variability (HRV), cortisol, dehydroepiandrosterone (DHEA), glucocorticoid sensitivity, and pro-inflammatory cytokines. The authors postulate that resilient individuals are characterized by lower concentrations of noradrenaline, $\mathrm{CRH}$ and pro-inflammatory cytokines, a decreased acoustic startle response, lower cardiovascular stress reactivity, higher concentrations of NPY and DHEA, and a higher HRV. Notably, with regard to cortisol and glucocorticoid sensitivity, depending on the outcome measure, (i.e., absence or presence of a particular illness), lower or higher concentrations may favor resilience. For instance, hyperactivity of the hypothalamic-pituitary-adrenal (HPA) axis has been found in melancholic depression, alcohol use disorder, and eating disorders (Chrousos 
2009). In contrast, posttraumatic stress disorder or somatic symptom disorders seem to be associated with diminished HPA activity. Finally, research into genetic factors fostering resilient trajectories has recently gained momentum. Accumulating evidence shows that polymorphisms within various genes that code for components of the HPA axis, such as $N R 3 C 1$ and $F K B P 5$, seem to play an important role in facilitating beneficial outcomes after the occurrence of a potential stressor (Zannas and West 2014).

\section{Cross-References}

Active Coping
Chronic Disease or Illness
Coping
- Hardiness
Life Events
- Minority Subgroups
- Optimism and Pessimism: Measurement
Positive Affectivity
- Resilience
- Self-Efficacy
- Self-Esteem
- Sense of Coherence
Social Support
- Stress
Stress, Early Life

\section{References and Further Reading}

Ahern, N. R., Kiehl, E. M., Lou Sole, M., \& Byers, J. (2006). A review of instruments measuring resilience. Issues in Comprehensive Pediatric Nursing, 29, 103-125.

Antonovsky, A. (1979). Health, stress, and coping: New perspectives on mental and physical well-being. San Francisco: Jossey-Bass.

Babatunde-Sowole, O., Power, T., Jackson, D., Davidson, P. M., \& DiGiacomo, M. (2016). Resilience of African migrants: An integrative review. Health Care or Women International, 37, 946-963.

Block, J. H., \& Block, J. (1980). The role of ego-control and ego-resiliency in the organization of behavior. In W. A. Collins (Ed.), Development of cognition, affect, and social relations: The Minnesota Symposia on child psychology. Hillsdale: Erlbaum.
Bonanno, G. A. (2004). Loss, trauma, and human resilience: Have we underestimated the human capacity to thrive after extremely aversive events? American Psychologist, 59, 20-28.

Bonanno, G. A., \& Diminich, E. D. (2013). Annual research review: Positive adjustment to adversity-trajectories of minimal-impact resilience and emergent resilience. Journal of Child Psychology and Psychiatry, 54, 378-401.

Bonanno, G. A., Westphal, M., \& Mancini, A. D. (2011). Resilience to loss and potential trauma. Annual Review of Clinical Psychology, 7, 511-535.

Charney, D. S. (2004). Psychobiological mechanisms of resilience and vulnerability: Implications for successful adaptation to extreme stress. The American Journal of Psychiatry, 161, 195-216.

Chrousos, G. P. (2009). Stress and disorders of the stress system. Nature Reviews Endocrinology, 5, 374-381.

Connor, K. M., \& Davidson, J. R. (2003). Development of a new resilience scale: The Connor-Davidson resilience scale (CD-RISC). Depression and Anxiety, 18, 76-82.

Deshields, T. L., Heiland, M. F., Kracen, A. C., \& Dua, P. (2016). Resilience in adults with cancer: Development of a conceptual model. Psycho-Oncology, 25, $11-18$.

Feder, A., Nestler, E. J., \& Charney, D. S. (2009). Psychobiology and molecular genetics of resilience. Nature Reviews Neuroscience, 10, 446-457.

Folkman, S., \& Lazarus, R. S. (1988). Manual for the ways of coping questionnaire. Palo Alto: Consulting Psychological Press.

Friborg, O., Hjemdal, O., Rosenvinge, J. H., \& Martinussen, M. (2003). A new rating scale for adult resilience: What are the central protective resources behind healthy adjustment? International Journal of Methods in Psychiatric Research, 12, 65-76.

Goubert, L., \& Trompetter, H. (2017). Towards a science and practice of resilience in the face of pain. European Journal of Pain, 21, 1301-1315.

Han, M. H., \& Nestler, E. J. (2017). Neural substrates of depression and resilience. Neurotherapeutics, 14, 677-686.

Kobasa, S. C. (1979). Stressful life events, personality, and health: An inquiry into hardiness. Journal of Personality and Social Psychology, 37, 1-11.

Liu, H., Zhang, C., Ji, Y., \& Yang, L. (2018). Biological and psychological perspectives of resilience: Is it possible to improve stress resistance? Frontiers in Human Neuroscience, 12, 1-12.

Martin, M. M., \& Rubin, R. B. (1995). A new measure of cognitive flexibility. Psychological Reports, 76, 623-626.

Pangallo, A., Zibarras, L., Lewis, R., \& Flaxman, P. (2015). Resilience through the lens of interactionism: A systematic review. Psychological Assessment, 27, $1-20$.

Rosenberg, M. (1965). Society and the adolescent selfimage. Princeton: Princeton University Press. 
Russo, S. J., Murrough, J. W., Han, M. H., Charney, D. S., \& Nestler, E. J. (2012). Neurobiology of resilience. Nature Neuroscience, 15, 1475-1484.

Sarason, I. G., Levine, H. M., Basham, R. B., \& Sarason, B. R. (1983). Assessing social support: The social support questionnaire. Journal of Personality and Social Psychology, 44, 127-139.

Scheier, M. F., Carver, C. S., \& Bridges, M. W. (1994). Distinguishing optimism from neuroticism (and trait anxiety, self-mastery, and self-esteem): A reevaluation of the life orientation test. Journal of Personality and Social Psychology, 67, 1063-1078.

Sherer, M., Maddux, J. E., Mercandante, B., PrenticeDunn, S., Jacobs, B., \& Rogers, R. W. (1982). The self-efficacy scale: Construction and validation. Psychological Reports, 51, 663-671.

Tan-Kristanto, S., \& Kiropoulos, L. A. (2015). Resilience, self-efficacy, coping styles and depressive and anxiety symptoms in those newly diagnosed with multiple sclerosis. Psychology, Health \& Medicine, 20, 635-645.

Wagnild, G. M., \& Young, H. M. (1993). Development and psychometric evaluation of the resilience scale. Journal of Nursing Measurement, 1, 165-178.
Walker, F. R., Pfingst, K., Carnevali, L., Sgoifo, A., \& Nalivaiko, E. (2017). In the search for integrative biomarker of resilience to psychological stress. Neuroscience \& Biobehavioral Reviews, 74, 310-320.

Watson, D., Clark, L. A., \& Tellegen, A. (1988). Development and validation of brief measures of positive and negative affect: The PANAS scales. Journal of Personality and Social Psychology, 54, 1063-1070.

Windle, G., Bennett, K. M., \& Noyes, J. (2011). A methodological review of resilience measurement scales. Health and Quality of Life Outcomes, 9, 1-18.

Woodward, E. N., Banks, R. J., Marks, A. K., \& Pantalone, D. W. (2017). Identifying resilience resources for HIV prevention among sexual minority men: A systematic review. AIDS and Behavior, 21, 2860-2873.

Ye, Z. J., Liang, M. Z., Li, P. F., Sun, Z., Chen, P., Hu, G. Y., Yu, Y. L., Wang, S. N., \& Qiu, H. Z. (2018). New resilience instrument for patients with cancer. Quality of Life Research, 27, 355-365.

Zannas, A. S., \& West, A. E. (2014). Epigenetics and the regulation of stress vulnerability and resilience. Neuroscience, 264, 157-170. 